\title{
O ESPORTE NAS LEIS ORGÂNICAS MUNICIPAIS E AS POLÍTICAS DE GESTÃO
}

\author{
Recebido em: 03/01/2017
}

Aceito em: 18/07/2017

\author{
Marco Aurélio Gonçalves Nóbrega dos Santos \\ Faculdade Estácio - Unidade Ourinhos \\ Ourinhos - SP - Brasil \\ Elisabete dos Santos Freire \\ Universidade São Judas Tadeu (USJT) \\ São Paulo - SP - Brasil \\ Flávia da Cunha Bastos \\ Universidade de São Paulo (USP) \\ São Paulo - SP - Brasil
}

RESUMO: O presente trabalho teve por objetivo analisar como o esporte, como direito social, tem sido inserido e considerado nos ordenamentos legais, isto é, nas Leis Orgânicas que compõem a política setorial dos 13 municípios pertencentes à UMMES (União dos Municípios da Média Sorocabana) do Estado de São Paulo. Foi possível identificar a ausência de definição do esporte enquanto direito social, o que reflete na construção de políticas públicas efetivas. Identificamos um baixo grau de exercício real da autonomia municipal numa perspectiva democrática ao esporte o que reflete na pouca ou nenhuma utilidade social e ou legislativa dos vereadores e ainda a nula e insignificante influência dos profissionais do esporte, os gestores na elaboração e participação da legislação municipal revelando a existência de uma lacuna entre poder legislativo e esporte dificultando a interlocução entre governo e sociedade.

PALAVRAS CHAVE: Organização e Administração. Lei Orgânica. Políticas Públicas. Atividades de Lazer.

\section{SPORTS IN MUNICIPAL ORGANIZATIONAL LAWS AND MANAGEMENT POLICIES}

ABSTRACT: The present work had as objective to analyze how the sport, as a social right, has been inserted and considered in the legal orders, that is to say, in the Organic Laws that make up the sectoral policy of the 13 municipalities belonging to UMMES (Union of Municipalities of Sorocabana Average) State of São Paulo. It was possible to identify the absence of definition of sport as a social right, which reflects in the construction of effective public policies. We identified a low degree of real exercise of municipal autonomy in a democratic perspective to the sport, which reflects in the little or no social and legislative utility of the city councilmen, and also the null and 
insignificant influence of sports professionals, managers in the elaboration and participation of municipal legislation revealing the existence of a gap between legislative power and sports, making it difficult to interlocate between government and society.

KEYWORDS: Organization and Administration. Organic Law. Public Policies. Leisure Activities.

\section{Introdução}

O esporte é fenômeno social cada vez mais presente e evidente na sociedade contemporânea, assumindo papel importante na vida das pessoas. Como tal, compete ao Estado, através dos municípios, a responsabilidade e o dever de investir no processo de democratização da prática esportiva. Nessa perspectiva, o esporte se insere como um direito social, garantido em diversas normas legais, de modo a promover o bem estar e desenvolver habilidades do cidadão e da sociedade.

Sarmento (2009) explica que o esporte moderno é um instrumento que oportuniza o desenvolvimento dos conceitos básicos da sociedade, como o cumprimento e obediência às regras, trabalho em conjunto e em equipe, ações de superação e voluntariado, condições de igualdade aos menos favorecidos e a busca pela melhor qualidade e estilo de vida de maneira mais efetiva. Contudo, para que o esporte possa desempenhar seu papel, é preciso que sejam elaboradas políticas que possam estimular a construção de programas adequadamente planejados pela administração pública, muitas vezes denominada de secretaria, coordenação, diretoria ou departamento (FEIX, 2007).

A Constituição Federal do País (BRASIL, 1988), em seu artigo 217 assegura o esporte como um direito social a todos os cidadãos brasileiros. Estados e municípios, por meio das legislações estaduais e as leis orgânicas municipais, têm autonomia para que definam suas políticas públicas e aplicação de recursos, responsabilizando assim 
seus governantes realizarem a gestão dessas em consonância com suas respectivas legislações, no caso dos municípios, as Leis Orgânicas (LO).

Diante disso, mesmo considerando o esporte reconhecido como direito de todos pela Carta Internacional da Educação Física e Esporte da UNESCO, de 1978; direito fundamental reconhecido pela Declaração Universal dos Direitos Humanos (ONU) e pela Constituição Federal de 1988, o que podemos observar é que os governos municipais o relegam a um segundo plano, sendo muitas vezes utilizado apenas com interesses políticos eleitoreiros nas campanhas políticas, em barganhas, conchavos e ainda como plataformas de campanha para conseguir votos (LINHALES, 2001; LINHALES \& PEREIRA FILHO， 1999; MANHÃES，2002; VERONEZ，2005; MEZZADRI et al., 2006; ROCHA e. al., 2007; STAREPRAVO, 2007).

No entanto, segundo Chemin (2007) é papel dos municípios elaborar políticas públicas que fomentem o esporte, à semelhança das demais áreas sociais, a fim de não só atender o cumprimento da Constituição Federal, mas principalmente de possibilitar à população o direito de adquirir o bem-estar e a qualidade de vida. Nesse sentido, a gestão municipal tem o dever de ordenar o pleno desenvolvimento das funções sociais nas cidades, entre eles o esporte e o acesso a sua prática democratizada.

Assim, é relevante a elaboração de um ordenamento legal capaz de garantir o amparo regulatório para implementação de políticas públicas consistentes, orientando as mudanças necessárias na gestão municipal de esporte. A Lei Orgânica é a lei maior de um município. Possui caráter genérico e constitucional, elaborada no âmbito do município, em consonância com as constituições federal e estadual.

Segundo Lima et al. (2011) ao pensar as políticas públicas de esporte e lazer como políticas de Estado há o entendimento de que elas refletem o programa de 
governo no aspecto econômico, social, cultural e na forma que são geridos. Ainda segundo os autores, ao considerar os âmbitos estaduais e municipais, não se tem informações seguras que subsidiem as políticas de esporte e lazer em suas diferentes vertentes, o que torna oportuno aprofundar sobre a situação dos municípios estudados em detrimento das políticas de esporte e esporte e lazer gerido pelo governo estadual.

O presente trabalho teve por objetivo analisar como o esporte, como direito social, tem sido inserido e considerado nos ordenamentos legais, isto é, nas Leis Orgânicas que compõem a política setorial dos 13 municípios pertencentes à UMMES (União dos Municípios da Média Sorocabana) do Estado de São Paulo, identificando e verificando qual o papel que o esporte assume nas respectivas leis como alvo de política social.

\section{Caminho Metodológico}

Esta pesquisa teve por objetivo estudar as políticas públicas municipais de esporte sob a ótica das Leis Orgânicas de municípios do Estado de São Paulo, identificando e verificando o conteúdo do ordenamento legal e regulatório. Trata-se de uma pesquisa documental de abordagem qualitativa, cuja principal finalidade é descrever e compreender o significado do objeto de estudo (THOMAS; NELSON e SILVERMAN, 2007). De acordo com Cervo e Bervian (2002), esse tipo de pesquisa busca esclarecer os fenômenos, por meio de documentos referenciados, a fim de analisar as contribuições culturais ou científicas do passado sobre determinado assunto ou problema.

Para que o objetivo fosse atingido, foram utilizadas as Leis Orgânicas dos 13 municípios pertencentes à UMMES (União dos Municípios da Média Sorocabana) do Estado de São Paulo. A UMMES está localizada na microrregião de Ourinhos que 
agrega municípios dentro da mesorregião administrativa de Assis, a saber: Bernardino de Campos (10.776 habitantes); Canitar (4.369 habitantes); Chavantes (12.437 habitantes); Espírito Santo do Turvo (4.244 habitantes); Ibirarema (6.725 habitantes); Ipaussu (13.663 habitantes); Óleo (2.673 habitantes); Ourinhos (103.035 habitantes); Ribeirão do Sul (4.446 habitantes); Salto Grande (8.787 habitantes); São Pedro do Turvo (7.198 habitantes); Santa Cruz do Rio Pardo (43.921 habitantes) e Timburi (2.646 habitantes) (IBGE, 2010). Com exceção de Ourinhos e Santa Cruz do Rio Pardo os demais municípios não possuem mais do que 15 mil habitantes. Estes municípios citados fazem parte dessa associação.

Com sua sede física instalada no município de Santa Cruz do Rio Pardo, a UMMES foi fundada em 16 de abril de 1994 com a proposta de oferecer serviços em formato de consórcio. O objetivo da entidade é a prestação de quaisquer serviços que possam contribuir para o fomento e a racionalização das atividades municipais, a defesa das atividades econômicas, sociais, esportivas e culturais de seus associados, seu bemestar e saúde. A saúde é a principal área dessa entidade na qual os municípios integrantes tem atendimento de exames médicos de média e alta complexidade em diversas áreas com consultas médicas especializadas. No setor de administração existem vários treinamentos e capacitações para as áreas especificas das prefeituras em seus serviços. Há também um consórcio de máquinas agrícolas, tratores, caminhões para prestar apoio e atendimento aos municípios em suas demandas e necessidades (UMMES, 2013). 
Figura 1: Mapa de Localização dos Municípios integrantes da UMMES
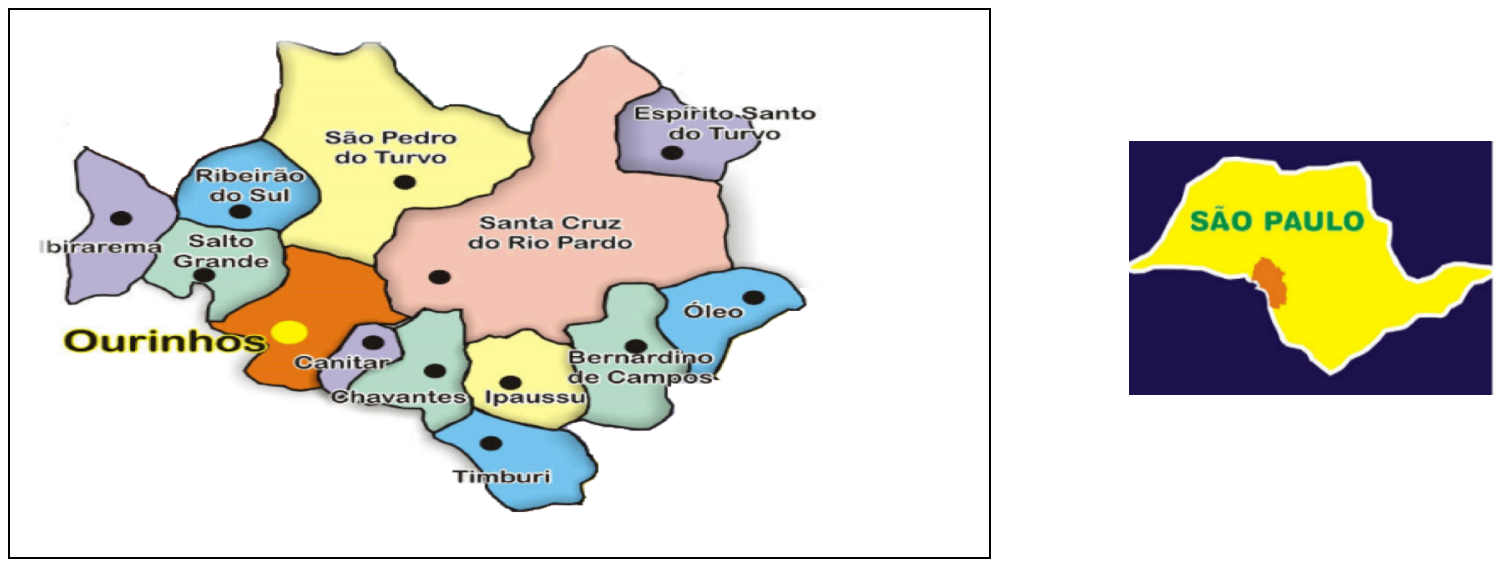

Fonte: Fundação SEADE, Estado de São Paulo e suas Regionalizações, 2015.

A caracterização do universo de estudo aponta que dos 13 municípios investigados, 8 possuem até 10 mil habitantes, 3 de 10 a 20 mil, 1 de 20 a 50 mil e 1 acima de 100 mil habitantes. Trata-se de uma microrregião do Estado com características de desenvolvimento econômico calcado na agropecuária, com a predominância da cultura da cana de açúcar e a criação de bovinos, atividades de apoio à agricultura, à prestação de serviços como os de saúde, transportes terrestres e os serviços prestados às empresas. O comércio, por sua vez, tem como principais componentes o varejo de produtos diversos, peças para veículos e varejo de vestuário (SEBRAE, 2013).

A pesquisa foi desenvolvida segundo as seguintes fases: acesso, aquisição e organização das referidas Leis, baseada em leitura utilizando critérios da análise de conteúdo; e análise crítica dos documentos. 
Os documentos das Leis Orgânicas foram obtidos nos sites das prefeituras municipais, disponibilizados publicamente conforme preconiza a Lei, ou seja, a Constituição de 1988 no seu artigo 37, que elevou a princípio constitucional da administração pública o princípio da publicidade, constituindo-se em garantia ao cidadão de controlar a atividade administrativa através dos mecanismos legais à sua disposição e também nos setores administrativos das respectivas entidades públicas.

Somente em um município que pertence a essa associação não foi possível o acesso à referida lei. Após a organização dos documentos foram desenvolvidas análises mediante leituras sucessivas e sistemáticas nas quais se buscou identificar as ações previstas pelos respectivos documentos.

Foi realizada uma análise descritiva de todas as informações contidas nas Leis Orgânicas, utilizando-se como recurso a Técnica de Análise de Conteúdo Temático, técnica esta pertinente para estudos desta natureza (BARDIN, 2009). Ela é baseada em decodificar um texto em diversos elementos, os quais são classificados e agrupados em eixos temáticos (RICHARDSON et al., 1999), para melhor compreensão do objeto pesquisado.

Foram destacados os documentos que descreviam alguma ação preconizada ou instituída como meta. Foi realizada, então, uma releitura desses documentos e identificados os seguintes eixos temáticos: a) esporte formal e informal; b) esporte e educação física; c) conselho municipal de esporte; d) orçamento para o esporte; e) esporte para pessoas com deficiência; f) instalações esportivas. Finalmente, foi realizada a análise crítica dos documentos, com a caracterização, a descrição e os comentários a partir de levantamento de assuntos recorrentes, interpretação e inferência (MOREIRA, 2005). 


\section{Resultados e Discussão}

Inicialmente fizemos a análise das Leis Orgânicas municipais obtidas no que se refere às suas promulgações e revisões. No Gráfico 1 verificamos que 10 municípios apresentaram suas Leis promulgadas entre 1990 a 1993, uma em 1999 e 2000 e uma não foi possível analisar. As revisões e atualizações das respectivas Leis aconteceram em 9 destes municípios no período entre de 2004 a 2010, com exceção de uma, revista em 2013 e 3 não tiveram nenhuma revisão.

Gráfico 1 - Período de Promulgação das Leis Orgânicas

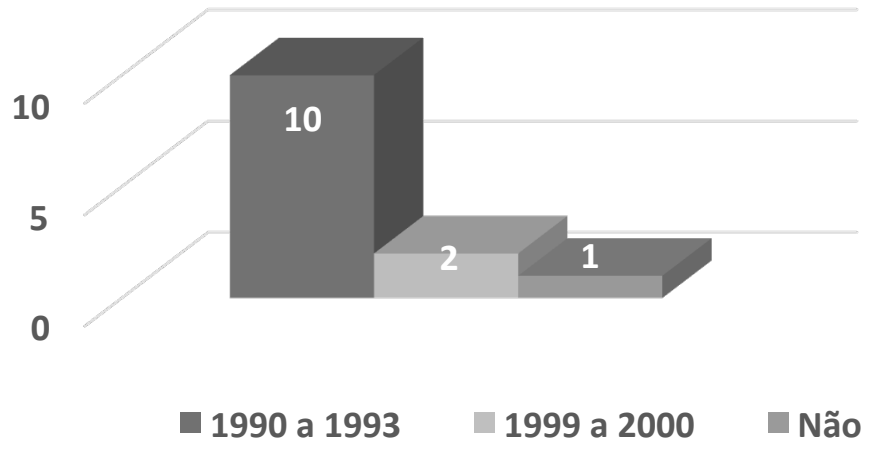

Assim, pudemos verificar que as referidas Leis não têm passado por processo de revisão, o que leva a compreensão de que existe uma falta de comprometimento do Poder Executivo com o Legislativo em estabelecer de fato a autonomia que lhes é permitida segundo a própria Constituição Federal em seu art. 18, já que são justamente nelas que são fixadas as atribuições, as obrigações e as competências que diz respeito aos municípios, as normas de tudo que for de interesse e peculiar a eles.

Quanto aos Eixos Temáticos elencados para identificação e análise, os resultados são apresentados para cada um deles: a) esporte formal e informal; b) esporte 
e educação física; c) conselho municipal de esporte; d) orçamento para o esporte; e) esporte para pessoas com deficiência; f) instalações esportivas.

\section{A) Esporte como direito social}

Foi possível perceber que os municípios pesquisados reproduzem, de forma geral, os textos propostos para o fomento ao esporte formal e não formal, de acordo com a Constituição Federal e a Constituição Estadual, com proporções variáveis. Assim, verifica-se que as disposições apresentadas são cópias de modelos de Leis Orgânicas entre si.

Artigo 180 - O Município fomentará as práticas desportivas formais e não formais, dando prioridade aos alunos da rede de ensino oficial e à promoção desportiva dos clubes locais. (Bernardino de Campos, Óleo).

Artigo 180 - O Município estimulará o desenvolvimento das ciências, das artes, das letras e da cultura em geral, esportes e lazer, observando o disposto na Constituição Federal e nesta Lei Orgânica. (Canitar, Espírito Santo do Turvo, Ipaussu e Santa Cruz do Rio Pardo).

Art. 122 - O Município apoiará e incentivará as práticas esportivas formais e não formais, como direito de todos, bem como o lazer como forma de integração social. (Ibirarema e Ribeirão do Sul).

Artigo 403. É dever do Município, apoiar e incentivar, com base nos fundamentos da educação física, o esporte, a recreação, o lazer, a expressão corporal, como formas de educação e promoção social e como prática sociocultural e de preservação da saúde física e mental do cidadão (Ourinhos).

Davies (2010) levantou algumas hipóteses para essas generalidades dos textos. A primeira delas é que os modelos de leis orgânicas podem ter sido vendidas ou fornecidas por consultores especializados ou até mesmo partidos políticos. A outra hipótese é que os elaboradores se limitaram a copiar outras Leis Orgânicas já promulgadas. 
Biondo et al. (s/d) afirmam que a Lei Orgânica determina a maneira pela qual a política e administrativamente o município irá seguir obedecendo aos princípios estabelecidos na Constituição Federal e nas Constituições Estaduais. Há de se ressaltar que ela deverá contemplar todos os aspectos que digam respeito ou tenham relevância no âmbito municipal, com destaque as peculiaridades e que visem desenvolvimento socioeconômico.

Estudos de Araújo; Dominici e Cardoso (2008) também constataram que os ordenamentos legais em São Luís do Maranhão regulamentam as políticas de esporte e eles se apresentam também de forma genérica, preconizam como direito do cidadão e dever do Estado. Nesse sentido, os autores revelam que existe a necessidade de políticas efetivas que realmente assegurem o esporte como direito social.

Diante disso, reafirmamos nesse estudo a generalidade com o tema esporte e consequentemente a falta de profundidade na sua abordagem, que resultam na dificuldade de melhor contribuir no processo de proposições de ações e intervenções que assegurem de fato o direito de acesso ao esporte.

Nesse sentido, Mezzadri et al. (2006) relatam em estudo realizado sobre políticas públicas para o esporte e o lazer nas cidades do Paraná que a elaboração das ações voltadas para o esporte são determinadas pelas vontades e interesses dos próprios governantes, sem planejamento prévio e envolvimento da sociedade nas decisões.

Bramante (2004) afirma que os setores de esporte e lazer são considerados como de menor importância nos planos de governos e Zingoni (2003) revela que a relação entre Legislativo e o esporte e lazer é muito pequena, que implica em certo descaso do poder Executivo, consequentemente não oferece ao Legislativo maior critério para defender os interesses do esporte e o compromisso com a sociedade. A autora revela 
ainda que é preciso ampliar o diálogo entre os agentes públicos e a sociedade civil dividindo e assumindo responsabilidades que oportunizem diagnósticos da realidade do esporte e lazer nos municípios.

Essas informações revelam uma questão muito presente no cenário brasileiro e principalmente nos pequenos municípios que é a dificuldade em reconhecer o esporte como problema político, que exige uma participação governamental mais ativa em ações de intervenção com a participação da sociedade na busca de assegurar o esporte como direito social de fato.

Bastos (2011) afirma que o Estado tem ação cada vez mais marcante ao desenvolvimento de políticas públicas de Esporte, incorporando-o no rol das políticas sociais, caracterizando-o por implementar e fomentar o esporte educacional, o esporte lazer e o esporte de rendimento com projetos específicos.

Estudos mostram dificuldades na execução de políticas públicas para o esporte em municípios brasileiros, entre elas estão falta de planejamento e pessoal especializado, assistencialismo e utilitarismo atribuídos ao esporte e carência de espaços, instalações esportivas e acesso (MEZZADRI et al., 2006; LINHALES, 2001; PERES e MELO, 2006).

De acordo com estudo realizado por Araújo e Magalhães (2008) revelou que o gestor municipal de esporte não tem domínio preciso sobre as legislações que regem as políticas públicas de esporte no município, entre elas está a Lei Orgânica além das principais diretrizes para o esporte nas esferas federal, estadual e municipal.

Almeida e Paula (2012) revelam que muitas vezes o poder público concebem a política de esporte com uma visão utilitária para compensar os problemas sociais, 
combater a violência, afastar crianças das ruas, melhorar a saúde da população. Porém, esse assistencialismo dificulta as reais ações de esporte como direito social.

É possível perceber a necessidade de uma gestão de política pública de esporte com maior comprometimento dos governantes, no que diz respeito à efetivação e garantia dessas políticas mediante progressos nas discussões para ações reais através da organização legislativa, participação da sociedade e gestão democrática. É fundamental que haja um estreitamento de relação entre governo e sociedade diante desse processo.

\section{B) Esporte e Educação Física}

Quanto a este tema, ressaltamos que em 3 destes municípios o esporte não aparece contemplado nas suas Leis, que mencionam a Educação Física como obrigatoriedade na rede de ensino e não dispõe o esporte como fenômeno social. Os textos também demonstram ser cópia de cópias de outras leis orgânicas municipais, considerando que os textos são idênticos. É possível que a ausência do Esporte na legislação seja resultado de um equívoco conceitual ou até mesmo a tendência de compreensão de que esporte e Educação Física são sinônimos.

Parágrafo $3^{\circ}$ - O Município orientará e estimulará, por todos os meios, a educação física, que será obrigatória nos estabelecimentos municipais de ensino e nos particulares que recebam auxílio do Município (Chavantes, São Pedro do Turvo e Timburi).

Oliveira (2008) também identificou em seu estudo que o esporte é considerado uma intervenção dentro da disciplina curricular do sistema de ensino municipal a da Educação Física no processo de escolarização. Estudo de Mezzadri et. al. (2006), realizado em municípios paranaenses, revelou que em alguns casos o Esporte e o Lazer contemplam fator educativo por estar inserido na Secretaria Municipal de Educação, 
mostrando um dos possíveis direcionamentos do entendimento do esporte em consonância com a estrutura administrativa das prefeituras, que se diferencia nos municípios e estados brasileiros (BOHME e BASTOS, 2016).

\section{C) Conselho Municipal de Esporte}

Os municípios de Canitar, Espírito Santo do Turvo, Ipaussu e Santa Cruz do Rio Pardo preveem em suas Leis Orgânicas a existência do Conselho Municipal de Esportes, os demais não contemplam o tema. Além disso, o mesmo artigo aparece nas Leis desses mesmos municípios, sem qualquer alteração em sua redação.

Artigo 188 - A lei regulará a composição, o funcionamento e as atribuições do Conselho Municipal de Educação, do Conselho Municipal de Cultura e do Conselho Municipal de Esportes.

Diante do exposto, identificamos que esses municípios apresentam também os textos de suas respectivas leis idênticas e possivelmente podemos considerar alguns fatores que justificam essas constatações.

O primeiro se deve pelo fato que os dois primeiros municípios citados são os mais novos, isto é, até o ano de 1990 eram distritos e se tornaram municípios a partir de 1991. Isto nos faz acreditar que ambos os municípios se apropriaram de Leis até então já elaboradas e buscaram adequá-las para seus municípios. Segundo dados do IPEA (2014) de 1984 a 2000 foram instalados 1405 municípios no país sendo que 94,5\% têm menos de 20 mil habitantes.

Outro fator em relação aos outros dois municípios pode ser entendido pela proximidade territorial, que poderia ter influenciado na elaboração das suas respectivas leis, fruto de articulações político-administrativas entre os mesmos no processo de sua construção e implantação. 
Segundo Tatagiba (2002, p. 54), os “[...] conselhos gestores de políticas públicas são espaços públicos de composição plural e paritária entre Estado e sociedade civil, de natureza deliberativa, cuja função é formular e controlar a execução das políticas públicas setoriais". Devem ser compostos por representantes do governo e da sociedade civil.

Mezzadri et al. (2006) entendem que a necessidade da criação e implantação dos Conselhos Municipais de Esporte, irão contribuir diretamente para o processo de democratização esportiva através da participação da sociedade e da população em geral. Os autores ainda reforçam que esse fortalecimento para a democratização do esporte só é possível com a participação da sociedade que controla as ações políticas públicas refletindo assim para o esporte como direito do cidadão.

Santos (2013) afirma que o Conselho Municipal de Esporte é um canal de intermediação de necessidades e interesses na área do esporte recebendo assim as demandas da sociedade para a democratização das ações esportivas no município. O autor ainda afirma que a sua existência oportuniza para uma maior mobilização da sociedade disseminando e discutindo em torno das políticas públicas de esporte. No entanto, considera que a estrutura dos Conselhos Municipais de Esporte é ainda muito precária com os cenários sendo considerados como frágeis.

Menezes; Oliveira e Souza (2012) afirmam que na gestão das políticas públicas do esporte municipal os Conselhos são formas institucionalizadas de participação popular que objetivam a discussão, a sugestão, o questionamentos, avaliação e as reivindicações inerentes as demandas relacionadas ao esporte.

A criação de Conselhos Municipais de Esporte é uma ação recente no que se refere as implantações pelas administrações públicas municipais que tem como papel 
determinar diretrizes para aplicação de recursos municipais para a área (BASTOS, 2008).

As primeiras informações a respeito da existência dos Conselhos Municipais de Esportes se deu em 2003 com a pesquisa Perfil dos Municípios Brasileiros - Esporte 2003 (IBGE, 2006). Em 2003, 658 municípios brasileiros possuíam esses órgão, representando $11,8 \%$ num total de 5557. As últimas informações são de 2009 com 623 municípios brasileiros têm os referidos órgãos, isso representa $11,2 \%$ e no Estado de São Paulo dos 645 municípios apenas 94 possuem esses órgãos, o que representa 14,6\% (IBGE, 2010 b).

Em estudo realizado por Mezzadri et al. (2006) em 15 municípios do Paraná sendo seis delas litorâneas com a população entre 5 mil e 35 mil habitantes e as outras nove com mais de 100 mil habitantes identificaram que nenhuma delas apresentou Conselho Municipal de Esporte. Apenas um único município, o maior entre eles que apresentou mas é especificamente administrativo. Outro município justificou que o prefeito vetou a existência do referido Conselho e mais um município que as ações esportivas são designadas pelas associações esportivas.

Miguel e Starepravo (2008) também investigaram uma cidade no Paraná e constataram a não existência do Conselho Municipal de Esporte e diante disso acreditam que por esse fato a política pública de esporte e lazer não se confirma como política pública democrática. Consideram ainda que a não existência do Conselho Municipal de Esporte deixa a população distante e desinformada em relação as atividades e ações que são realizadas de forma aleatória e eventual, sem planejamento.

Oliveira (2008) em seu trabalho que investigou duas cidades na Bahia identificou que não existe leis que criam os conselhos municipais de esporte e lazer, o 
que reforça os dados encontrados pelo IBGE em 2003 que indicavam que na Bahia apenas 25 cidades num total de 417 apontam existir os referidos conselhos, o que representa $6,0 \%$, refletindo assim a fragilidade no ordenamento legal nos municípios do Estado em relação ao esporte.

Corroboram com Oliveira (2008) os estudos de Silva; Santos e Ávila (2013) que também investigaram um município baiano no qual identificaram a contemplação da criação do Conselho Municipal de Esporte regulamentado através de lei complementar, porém, o mesmo não fora criado efetivamente na prática. Outro estudo relativo a município baiano, de Santos; Silva e Oliveira (2015) sobre as políticas públicas frente as prerrogativas da política nacional de esporte em um município baiano, verificou que não existe o conselho de esporte no município, o que o mesmo seria um espaço importante para o diálogo entre gestor e população.

O mesmo foi observado por Menezes; Oliveira e Souza (2012) nas cidades da região metropolitana do Recife, que identificaram também ausência dos Conselhos Municipais de Esporte.

Da Mata (2011) em seu trabalho sobre a política pública de esporte e lazer na cidade de João Pessoa na Paraíba identificou a criação, composição e funcionamento do Conselho Municipal de Esporte através da Lei n. 8994 de 20/12/2000 e depois através da Lei n.10.692 de 26/12/2005 na qual o referido Conselho deixa de estabelecer vínculo com a Secretaria Municipal de Turismo e Esporte e passa para a Secretaria Municipal de Educação e Cultura. No entanto, nos dois casos o referido Conselho nunca fora efetivado.

No estado de São Paulo, os dados mais recentes são do Núcleo de Políticas Públicas (NPP) ligado à Procuradoria Geral de Justiça do Ministério Público de São 
Paulo que em agosto de 2013 traçou um diagnóstico preliminar sobre os Conselhos de Políticas Públicas nos municípios do Estado. No que se refere aos Conselhos Municipais de Esporte, 45 municípios possuíam, o que representa 7\% dos 645 municípios (SÃO PAULO, 2014).

Mezzadri et al. (2006) entendem que a necessidade da criação e implantação dos Conselhos Municipais de Esporte, irão contribuir diretamente para o processo de democratização esportiva através da participação da sociedade e da população em geral. Os autores ainda reforçam que esse fortalecimento para a democratização do esporte só é possível com a participação da sociedade que controla as ações políticas públicas refletindo assim para o esporte como direito do cidadão.

Santos (2013) afirma que o Conselho Municipal de Esporte é um canal de intermediação de necessidades e interesses na área do esporte recebendo assim as demandas da sociedade para a democratização das ações esportivas no município. O autor ainda afirma que a sua existência oportuniza para uma maior mobilização da sociedade disseminando e discutindo em torno das políticas públicas de esporte.

Menezes; Oliveira e Souza (2012) afirmam que na gestão das políticas públicas do esporte municipal os Conselhos são formas institucionalizadas de participação popular que objetivam a discussão, a sugestão, o questionamentos, avaliação e as reivindicações inerentes as demandas relacionadas ao esporte.

Os dados obtidos no presente estudo e em municípios de outras regiões do País revelam que a ausência de Conselho Municipal revela a fragilidade para assegurar o direito social do esporte, pois mostra as dificuldades e o distanciamento da sociedade junto aos governantes e gestores na busca de implantação de políticas públicas de esporte que sejam efetivas e eficazes. 
Diante disso, o que podemos verificar nas realidades estudadas e em nosso estudo que as políticas públicas de esporte e lazer apontam para a falta de iniciativas que garantam a participação da população através da existência dos Conselhos Municipais de Esporte e Lazer. Nesse sentido, parece haver um entendimento equivocado ou até o desconhecimento dos agentes políticos em relação à participação da sociedade na formulação e acompanhamento das políticas públicas, já que os mesmos não se utilizam desse canal de participação. $\mathrm{Na}$ verdade, como afirmam Mezzadri et al. (2006), se faz necessário rever essas relações entre os políticos, os gestores públicos e a sociedade para buscar as soluções, atender as necessidades e as demandas sociais dos municípios.

\section{D) Orçamento para o esporte}

No que se refere a orçamento, recursos e infraestrutura para o esporte, identificamos apenas referências nas Leis dos municípios de Óleo (Art. 199) e Ourinhos (Art. 409):

Art. 199 - As ações do poder Público e a destinação de recursos orçamentários para o setor darão prioridade: I - ao esporte educacional, o esporte comunitário e, na forma da lei, ao esporte de alto rendimento; II - ao lazer popular; III - à construção e manutenção de espaços devidamente equipados para as práticas esportivas e de lazer.

Artigo 406. O Município destinará recursos orçamentários para incentivar: I - o esporte formação, o esporte participação, o lazer comunitário, e, na forma da lei, o esporte de alto rendimento; III - a criação e manutenção de espaços próprios e equipamentos condizentes às práticas esportivas, recreativas e de lazer da população (Ourinhos).

Mais uma vez pudemos verificar que tais textos caracterizam como cópias da Constituição Estadual (SÃO PAULO, 1989), com as necessárias adaptações e supressões conforme seu Artigo 266 (As ações do Poder Público e a destinação de 
recursos orçamentários para o setor darão prioridade: I - ao esporte educacional, ao esporte comunitário e, na forma da lei, ao esporte de alto rendimento; II - ao lazer popular).

Embora esses municípios estabeleçam em suas Leis Orgânicas os recursos orçamentários, não explicitam quais os valores percentuais mínimo deverão ser aplicados ao esporte de forma a atender plena e satisfatoriamente as necessidades e interesses da população dos municípios em questão.

Os primeiros estudos e reflexões sobre o tema foram realizados no final da década de 1990 e início dos anos 2000. Castellani Filho (1999) observou que as administrações municipais dos Estados do país destinam cerca de 0,4\% em recursos para o esporte, lazer e a cultura, o que considera um investimento insuficiente considerando as reais necessidades e demanda para construção e manutenção de instalações, contratação e qualificação de profissionais. Já Zingoni (2003, p. 220) afirma que "[...] em geral, nas prefeituras, as secretarias de esporte e lazer são as que recebem a menor fatia do bolo orçamentário, induzindo a espetacularização do esporte e lazer como forma de atrair patrocinadores."

$\mathrm{Na}$ última década, novos estudos foram realizados em diferentes estados e regiões do País. Miguel e Starepravo (2008) ao estudarem municípios paranaenses identificaram que $2 \%$ dos orçamentos municipais são destinados ao esporte e lazer, sendo que $90 \%$ destinado ao esporte e $10 \%$ para o lazer. Ressaltam que não são explicitados os valores para atender o esporte educacional, rendimento ou outra manifestação esportiva.

Mezzadri et al., (2006) ao também ao estudarem municípios paranaenses identificaram no orçamento das secretarias municipais de esporte e lazer que o maior 
registro foi em um município, com aproximadamente $2,74 \%$ do orçamento, com os demais municípios destinando $1,5 \%$, e o menor, $0,5 \%$ do total de recursos destinados aos municípios para o desenvolvimento de ações para o esporte e lazer.

Elias et al. (2007) pesquisaram um município no Maranhão e identificaram que o valor destinado ao esporte e ao lazer é insuficiente, já que fora aprovado para o ano um montante de $\mathrm{R} \$ 220.000,00$ (duzentos e vinte e mil reais), o que representa aproximadamente $1,5 \%$ do orçamento municipal. Rocha et al. (2007) pesquisaram 5 municípios baianos e identificaram que a maioria das prefeituras não possuem uma política de orçamento/financiamento e consequentemente ações desordenadas relacionadas aos programas de esporte e lazer. Vale ressaltar que em um destes municípios $88 \%$ do orçamento para a pasta do esporte são destinados exclusivamente para a aquisição de materiais esportivos.

O Estado de São Paulo possui 645 municípios com uma população de 41.262.199 milhões em 2010 e estimativa de 44.396.484 milhões em 2015 sendo que 158 municípios possuem até 5 mil habitantes, 119 de 5 a 10 mil e 226 de 10 a 50 mil (IBGE, 2010). O orçamento para o ano de 2015, através da Lei no 15.646 de 23/12/2014 foi de mais de duzentos e quatro bilhões de reais e para 2016, R\$ 206.864.665.868,00. Para a Secretaria de Esporte, Lazer e Juventude foram destinados em 2015 mais de duzentos e cinquenta e cinco milhões de reais e para 2016, $\mathrm{R} \$ 207.884 .753,00$, o que representa $0,012 \%$ e $0,010 \%$ dos orçamentos (SÃO PAULO, 2015).

Dada a diferença dos porcentuais citados na literatura entre municípios de outros estados e a não citação sobre o tema na maioria dos municípios estudados nas leis orgânicas e frente aos dados relativos aos últimos orçamentos do Estado de São Paulo, 
realizamos levantamento de dados complementares em outras fontes para buscar informações sobre esse tema.

Nesse sentido, levantamos os Convênios da Secretaria de Esporte, Lazer e Juventude do Estado de São Paulo, no período compreendido de 01/01/2010 à 07/09/2015, e identificamos que foram celebrados 919 Convênios num total de R\$ $72.611 .310,57$.

Quanto aos municípios pertencentes à UMMES verificamos que foram firmados 12 convênios totalizando $\mathrm{R} \$ 1.431 .000,00$, o que representam de $0,013 \%$ a $0,019 \%$ de todos os convênios celebrados no Estado entre 2010 e 2014 (QUADRO 1).

\begin{tabular}{|c|c|c|c|}
\hline ANO & MUNICÍPIO & CONVÊNIO & VALOR \\
\hline $2010 / 2012$ & Chavantes & Revitalização da Piscina Pública & $\mathrm{R} \$ 150.000,00$ \\
\hline $2010 / 2012$ & Espírito Santo do Turvo & Investimento em Obras & $\mathrm{R} \$ 70.000,00$ \\
\hline $2010 / 2012$ & Ipaussu & Reforma da Piscina Pública & $R \$ 150.000,00$ \\
\hline 2010/2012 & Ipaussu & Construção da Pista de Skate & $\mathrm{R} \$ 50.000,00$ \\
\hline $2012 / 2014$ & Ipaussu & Cobertura da Quadra Poliesportiva & $\mathrm{R} \$ 140.000,00$ \\
\hline $2012 / 2013$ & Óleo & Esporte Social - Serviços & $\mathrm{R} \$ 41.600,00$ \\
\hline $2012 / 2013$ & Óleo & Esporte Social - Consumo & $\mathrm{R} \$ 3.600,00$ \\
\hline $2011 / 2011$ & Ourinhos & Realização dos Jogos Regionais do Idoso & $\mathrm{R} \$ 120.000,00$ \\
\hline $2008 / 2014$ & Ourinhos & Construção de Área de Lazer no Jd. Industrial & $\mathrm{R} \$ 64.000,00$ \\
\hline $2010 / 2012$ & Santa Cruz do Rio Pardo & Investimentos em Obras & $\mathrm{R} \$ 342.000,00$ \\
\hline $2012 / 2014$ & Salto Grande & Reforma e ampliação do Ginásio de Esporte & $\mathrm{R} \$ 120.000,00$ \\
\hline 2012/2014 & Salto Grande & Construção de Quadra coberta com Vestiários & $\mathrm{R} \$ 200.000,00$ \\
\hline
\end{tabular}

Fonte: Secretaria da Fazenda do Estado de São Paulo, 2015.

Dos convênios estabelecidos no período, apenas 7 dos 13 municípios pertencentes à UMMES foram contemplados e dos 12 convênios, 9 são para construção, reforma e ampliação de instalações de esporte e lazer e 3 foram destinados a programas, projetos e eventos.

Há de se ressaltar que os municípios não podem ficar somente na dependência de recursos oriundos do Governo Estadual e/ou Federal através a celebração de convênios, emendas parlamentares, mas é imprescindível que haja uma perspectiva crítica e ampliada que possibilitem iniciativas articuladas de discussões entre poder 
público e sociedade na construção conjunta e coletiva de políticas públicas de esporte e lazer que atendam as reais necessidades e interesses da população.

Corroboramos com a visão de Zingoni (2003) de que as políticas de esporte e lazer, através de suas gestões, são utilizadas como plataforma política e ocorre muitas vezes descontinuidade de projetos propostos para serem efetivados, que são evidenciadas com doação de material esportivo ou cessão de equipamentos esportivos. Considerando o exposto, podemos afirmar que não existe uma preocupação dos municípios pesquisados em desenvolver um política pública de orçamento/financiamento para o esporte. Isto mostra a precariedade em relação a como as políticas públicas de esporte se apresentam em relação à destinação de recursos orçamentários que sejam compatíveis com as necessidades e as demandas dos municípios, obviamente considerando também as particularidades de cada município no sentido de possibilitar a todo cidadão o exercício do direito ao esporte.

\section{E) Esporte para pessoas com deficiência}

Em relação as atividades esportivas para os portadores de deficiências, identificamos que 3 dos municípios estudados contemplam esse tema, os demais não fazem referência, considerando mais uma vez que os textos legais preconizam a mesma visão contida na Constituição Estadual:

$\mathrm{V}$ - à adequação dos locais já existentes e previsão de medidas necessárias quando da construção de novos espaços, tendo em vista a prática de esportes e atividades de lazer por parte dos portadores de deficiências, idosos e gestantes, de maneira integrada aos demais cidadãos.

Parágrafo único - O Poder Público estimulará e apoiará as entidades e associações da comunidade dedicadas às práticas esportivas.

Artigo 267 - O Poder Público incrementará a prática esportiva às crianças, aos idosos e aos portadores de deficiências (SÃO PAULO, p. 69, 1989). 
Artigo 404. As unidades esportivas do Município deverão estar voltadas ao atendimento esportivo, cultural, da recreação e do lazer da população, destinando atendimento específico às crianças, aos adolescentes, aos idosos e aos portadores de deficiência (Óleo).

Artigo 405. O Município, na forma da lei, promoverá programas esportivos destinados aos portadores de deficiência, cedendo equipamentos fixos em horários que lhes permitam vencer as dificuldades do meio, principalmente nas unidades esportivas, conforme critérios definidos em lei (Ourinhos).

Artigo 180 Parágrafo $5^{\circ}$ Item II - ações de construir, equipar e manter centros poli esportivos e de centros de convivência e lazer cultural comunitários, respeitando o acesso e circulação de pessoas portadoras de deficiência, bem como de espaços destinados à cultura e apresentações artísticas;

III - aproveitamento e adaptação de rios, vales, colinas, lagos, matas e outros recursos naturais, como locais de passeio e distração.

$\S 6^{\circ}$ - No tocante às ações a que se referem os incisos do parágrafo anterior, o Município garantirá a participação de pessoas deficientes, nas atividades desportivas, recreativas e de lazer, incrementando o atendimento especializado (Santa Cruz do Rio Pardo).

No primeiro município verificamos que o texto preconiza o atendimento aos portadores de deficiência com a promoção de programas esportivos. O segundo município na sua Lei vai além, dispondo que as instalações sejam construídas, equipadas e mantidas em condições de atender as pessoas portadoras de deficiência e ainda garantir a sua participação em atividades esportivas e recreativas com atendimento especializado. Já o terceiro município aborda o acesso das pessoas portadoras de deficiência não só nos espaços esportivos, prevê que na adaptação de espaços públicos haja e a garantia de participação dos mesmos.

Foi também a partir da Constituição Federal de 1988 que as pessoas com deficiência começaram a ter seus direitos assegurados por intermédio das leis nos diversos âmbitos, nas quais podemos citar o Artigo 217 da Emenda Constitucional no 45/2004 que considera dever do Estado fomentar práticas desportivas como um direito de todos; a Lei de Diretrizes e Bases da Educação Nacional (Lei n. 9.394/96) que se 
refere ao direito a educação com atendimento especializado aos portadores de deficiência na rede regular de ensino e as Leis $\mathrm{n}^{\circ} 10.048 / 00$ e 10.098/00 que estabelecem normas gerais e critérios para a acessibilidade aos espaços públicos, transportes e edificações (ANDRADE et al., 2014).

A própria Política Nacional de Esporte revela em seus diagnósticos iniciais sobre a prática de esporte e lazer um cenário que o país ainda caminhava lentamente no processo de conhecimento das ações, as estruturas existentes eram consideradas insuficientes e defasadas, limitando ainda mais a elaboração de políticas públicas eficientes (BRASIL, 2005). Mais tarde, a Política Nacional de Saúde da Pessoa Portadora de Deficiência firma a parceria com o Ministério do Esporte para a implementação e o acompanhamento de programas esportivos e de atividades físicas para as pessoas com deficiência com base no conceito de qualidade de vida (BRASIL, 2009a).

Entre os programas podemos destacar o Segundo Tempo (PST), que é um programa aborda a deficiência com seu conceito, apresentando os tipos, as características e os procedimentos pedagógicos das atividades desenvolvidas. Entretanto, na avaliação geral do Programa Segundo Tempo foi observado que os alunos que possuem algum tipo de deficiência correspondem a menos de $1 \%$ e ainda que tanto coordenadores como monitores de núcleos não têm nenhuma experiência com esses alunos.

Outro programa federal que é destinado para toda a comunidade, o Esporte e Lazer na Cidade (PELC), tem entre suas três vertentes duas voltadas ao atendimento a pessoas com deficiência através de atividades esportivas, recreativas e de lazer: o programa Todas as Idades e o Vida Saudável, esse último voltado exclusivamente para 
maiores de 45 anos ou com deficiência e considerados sedentários. O processo de controle e avaliação revela que apenas $2 \%$ dos participantes do Programa Esporte e Lazer na Cidade possuem deficiência, sendo dividida proporcionalmente entre física e intelectual; contudo, 4,8\% dos participantes do programa afirmaram conviver com pessoas com deficiência em casa (SOUSA et al., 2010).

No Estado de São Paulo existem diversos projetos que visam a inclusão da pessoa com deficiência na prática do esporte. Entre eles podemos destacar o Programa Esporte sem Limites, do município de Barueri e o do governo do Estado de São Paulo que disponibiliza os equipamentos de ginástica no Parque do Ibirapuera. A Associação Desportiva para Deficientes/São Paulo e Handebol em Cadeira de Rodas na cidade de Sorocaba, que são instituições não governamentais desenvolvem atividades para esse público alvo (BARROZO et al., 2012).

Não identificamos um levantamento sobre a prática e a estrutura esportiva relacionadas a pessoas com deficiência. Este cenário compromete ainda mais a viabilização da implantação de políticas públicas abrangentes e eficazes, o que muitas acabam por ceder espaço para ações imediatistas, aleatórias e que visam resultados em curto prazo. Nesse sentido, Azevedo; Barros (2004) consideram que para que o esporte seja uma poderosa ferramenta no processo de inclusão social aos portadores de deficiência é imprescindível que ele esteja devidamente alinhado com uma política social que englobe governo e sociedade, necessitando de conscientizar da sua grande importância dentro dos governos.

Estudo realizado por Elias et al. (2007) revelou que a participação em atividades de esporte e lazer pelos portadores de deficiência tiveram $1 \%$ a $2 \%$ de adesão, porém esse índice não reflete só em relação ao número de participantes, mas reflete também o 
fato das pessoas terem dificuldade de acesso as atividades e às instalações limitando parte da população de deficientes a participarem das ações esportivas. De acordo com Melo (2003) ele conceitua como "minorias sociais".

Silva (2012) aponta a existência de uma lei estadual no Espírito Santo que menciona o desenvolvimento do esporte na perspectiva do lazer às pessoas com deficiência, mas também não mencionam a aplicabilidade da referida lei nos municípios capixabas. Também em relação a Lei Orgânica, estudo de Santos; Silva e Oliveira (2015) ao analisar a Lei Orgânica de um município baiano também revelou o que identificamos no presente estudo, ou seja, o texto que trata do fomento da prática esportiva para pessoas portadoras de deficiência encontra-se em consonância com a legislação federal e estadual, não explicita as ações, programas e projetos, apenas menciona a garantia do direito ao acesso a prática do esporte, o que não sinaliza para a realização dos mesmos.

Da mesma forma Miguel e Starepravo (2008) ao pesquisarem um município paranaense de porte médio/grande verificaram não existir ações e projetos que sejam voltados às pessoas portadoras de deficiência. Ainda encontramos os estudos de Oliveira (2008) na região nordeste e metropolitana da Bahia, Starepravo (2007) em municípios paranaenses, Galindo e Moraes no Amapá $(2004 ; 2005)$ nos quais fazem menção ao esporte como direito social, qualidade de vida, esporte educacional, ações e projetos direcionados ao rendimento e não fazem referência ao acesso e muito menos a participação de pessoas com deficiência em programação e projetos desenvolvidos pelas administrações locais.

\section{F) Instalações esportivas}

Sobre as estruturas esportivas, instalações, equipamentos, construções, manutenções identificamos menção nas Leis Orgânicas pesquisadas de 4 municípios, as quais mostraram uniformidade nos seus textos, o que nos levou a compreensão mais 
uma vez de que os mesmos se limitaram a copiar outras LOs em elaboração ou já promulgadas.

Art. 199

III - à construção e manutenção de espaços devidamente equipados para as práticas de esportivas e o lazer;

IV - à adequação dos locais já existentes e previsão de medidas necessárias quando da construção de novos espaços, tendo em vista a prática de esportes e atividades de lazer por parte dos portadores de deficiência, idosos e gestantes, de maneira integrada aos demais cidadãos (Óleo).

Art. 406

III - à construção e manutenção de espaços devidamente equipados para as práticas de esportivas e o lazer;

IV - à adequação dos locais já existentes e previsão de medidas necessárias quando da construção de novos espaços, tendo em vista a prática de esportes, da recreação e do lazer por parte dos portadores de deficiência, idosos e gestantes, de maneira integrada aos demais cidadãos.

Art. 409 - A Lei definirá a preservação, utilização pela comunidade e os critérios de mudança de destinação de áreas municipais ocupadas por equipamentos esportivos de recreação e lazer, bem como a criação de novas (Ourinhos).

Art. $151-3^{\circ}$ - A construção e manutenção de espaços devidamente equipados para práticas esportivas e de lazer (Ribeirão do Sul).

Art. 180 - Parágrafo $5^{\circ}$ - II - ações de construir, equipar e manter centros poliesportivos e de centros de convivência e lazer cultural comunitários, respeitando ao acesso de pessoas portadoras de deficiência, bem como espaços destinados à cultura e apresentações artísticas (Santa Cruz do Rio Pardo).

Segundo Amaral (2014) o processo de construção de políticas públicas para o esporte deve se considerar não só as ações, programas e projetos, necessidades e interesses da população, mas também o acesso aos espaços e as instalações adequadas e apropriadas para as práticas esportivas. Nesse sentido, a autora revela ainda que a legislação também é importante nesse processo das políticas públicas já que irão auxiliar a forma que essas instalações serão geridas pelo poder público o que considera 
que as mesmas são um dos fatores fundamentais para o desenvolvimento do esporte em qualquer de suas dimensões: educacional, lazer e rendimento.

Mazzei et al. (2012) ao pesquisarem programas públicos federais como o Segundo Tempo e Esporte e Lazer da Cidade, não identificam a realidade das instalações esportivas nos municípios atendidos no que se refere as suas condições para atender a população, as demandas, necessidades, no sentido de buscar a melhoria e ampliação das condições até então já existentes, o que evidencia na falta do controle do Estado em relação aos locais de prática esportiva. No segundo programa verificaram que não há evidencias documentais e publicações que apontam para o controle dos locais da prática esportiva dos referidos municípios contemplados pelo programa.

Corrobora com o estudo de Mazzei et al. (2012) o estudo de caso de Pedroso et al. (2012) que abordou as instalações públicas esportivas do Recife evidenciando o distanciamento da gestão do poder público em detrimento da demanda da população. Os autores consideram que gestão de instalações esportivas se referem ao planejamento, construções e ampliações de espaços e equipamentos esportivos, acessibilidade, manutenção e que estão diretamente relacionadas com a gestão de ações, programas, projetos.

De acordo com Mezzadri (2011), a construção de instalações esportivas nos pequenos municípios é geralmente custeada pelo Governo Federal ou Estadual que destinam a maior parte dos recursos a essas cidades. Outro cenário bastante presente atualmente é a celebração de convênios, emendas parlamentares dos deputados que contemplam aos municípios recursos para a instalação, construção e ampliação de espaços esportivos em troca de apoio político, como verificamos no item anterior.

Em consonância ao parágrafo anterior, segundo dados da Secretaria de Esporte, Lazer e Juventude do Estado de São Paulo (SELJ) em 2014 no Estado de São Paulo 
foram entregues aproximadamente 256 academias ao ar livre a 160 municípios por meio de emendas parlamentares. Em 2015 apenas um deputado deu entrada em mais de 43 emendas relativas a esportes e lazer ao projeto de Orçamento do Estado de São Paulo para 2016. As referidas emendas se referem tanto a programas para todo o Estado como para intervenções específicas em municípios (SÃO PAULO, 2015 b).

Além destes fatores acima mencionados demonstrando o interesse mais político sobre as instalações esportivas nos municípios, outra forte influência que podemos considerar visando a criação e disponibilização de mais e melhores instalações esportivas aos municípios são os grandes eventos que o Brasil vem sediando ao longo desses anos como os Jogos Pan-Americano 2007, Copa do Mundo 2014, Olimpíadas e Paralimpíadas 2016. Entretanto, para que o poder público dos municípios principalmente possa cumprir de fato seu papel político e social é relevante pensar em instalações que possibilitem maior diversidade e acesso levando em conta os interesses e necessidades da população (CONSTANTINO, 1999).

Nesse sentido, Cunha (2007) afirma que as instalações esportivas também fazem parte de uma política pública de esporte, pois significa organizá-las, mantê-las, ampliálas com imposição de regras, já que caso as referidas sejam implantadas de forma desordenada e que não atendam a necessidade dos cidadãos irão refletir de forma negativa. Uma política de avaliação e controle deve ser uma preocupação por parte dos governantes.

Em consonância com o exposto, para Da Costa (2005) a prática esportiva deve ser realizada em lugares apropriados, com princípios, regras e aspirações esportivas. Constantino (1999) afirma que as instalações esportivas são fundamentais para desenvolver o esporte e devem atender as necessidades da sociedade. Além disso, para 
Cunha (2007) as instalações esportivas são responsáveis por oportunizar e oferecer a prática esportiva de forma continuada, o que podemos afirmar no sentido de democratização do esporte.

Já estudos realizados no Brasil que abordam a questão da legislação dos municípios e o que elas se referem em relação as instalações esportivas têm sido realizados recentemente. Da Mata (2011) em sua pesquisa que analisou a Lei Orgânica no município de João Pessoa/PB identificou na referida lei referência à construção de instalações e equipamentos esportivos, o que também pudemos identificar em nosso estudo. Porém, em ambos os estudos as leis não preveem como que essas instalações serão geridas e mantidas para garantir o direito social de acesso, isto é, a democratização da prática esportiva.

Da mesma forma, Elias et al. (2007) ao estudar um município do Maranhão identificou na Lei Orgânica a celebração de convênios com associações esportivas para reforma e restauração de instalações esportivas desde que assegurem a utilização das mesmas pelo poder público garantindo o acesso ao esporte pela população gratuitamente. Ao estudarem a Lei Orgânica do município de São Luís no Maranhão Araújo; Dominici e Cardoso (2008) mencionam que o documento aborda a responsabilidade de forma bastante genérica ao se referirem à construção de espaços públicos para o esporte, pois ela não define claramente e ainda prioriza a construção de espações destinados as práticas esportivas do esporte de rendimento em detrimento dos espaços públicos que favoreçam o acesso de forma democrática.

Encontramos ainda o estudo de Silva (2012) que identificou a existência de uma Lei Estadual no Espírito Santo, chamada de Pró-Esporte n. 9.365/09 cujo objetivo é 
promover o esporte escolar na construção, recuperação e ampliação de instalações esportivas.

Numa outra abordagem, Souza (2014) pesquisou as instalações esportivas do município de Rio Branco - Acre e os resultados revelaram que a maioria das instalações atendem as modalidades esportivas de formação; existe maior predominância de quadras abertas com pisos irregulares, na maioria de areia; mais de $66 \%$ das instalações apresentam deficiências e isso se agrava por não haver manutenções preventivas; a distribuição das instalações esportivas no município mostram um desequilíbrio territorial o que reflete em número insuficientes dependendo da região. Por fim identificou que não existem mecanismos de planejamento, concepção e distribuição espacial das instalações e que o modelo de gestão adotado é a gestão direta (SOUZA, 2014)

Sarmento (2005), ressalta que é necessário existir a integração das ações do poder local numa política de esporte; o ordenamento territorial dos equipamentos; a formação de equipes municipais de gestão e manutenção de instalações visando garantir melhor aplicação dos recursos e atendendo a demanda da sociedade. Deve haver uma correlação e evolução dessas áreas.

Portanto, o acesso e a democratização do esporte estão diretamente relacionados com a oferta que é disponibilizada com os espaços, ambientes e infraestruturas para a prática esportiva. Cabe ao poder público a criação e cumprimento de políticas públicas de esporte que permitam o acesso facilitado ao esporte pela população, atendendo suas necessidades e que estas sejam geridas de forma eficiente de forma plena e contínua. 


\section{Considerações Finais}

O desenvolvimento do presente estudo que analisou as Leis Orgânicas de 13 municípios paulistas possibilitou um maior detalhamento em alguns aspectos no que diz respeito ao esporte como direito social e as diretrizes para as políticas públicas de esporte inseridas nas respectivas leis.

O estudo das leis orgânicas municipais dos municípios pertencentes à UMMES, em especial no que se refere ao papel que o esporte assume nas políticas públicas da região nos permitiu verificar a falta de definição do esporte enquanto direito social. Essa constatação tem reflexo direto na construção de políticas públicas efetivas pelo poder público, ou seja, ao ser tratado de forma genérica acabam por não garantir o estabelecimento de políticas públicas sistematizadas ao esporte.

Identificamos um baixo grau de exercício real da autonomia municipal numa perspectiva democrática ao esporte o que reflete na pouca ou nenhuma utilidade social e ou legislativa dos vereadores que se limitaram a copiar as respectivas leis e muitas vezes de forma incompetente e ainda a nula e insignificante influência dos profissionais do esporte, os gestores na elaboração e participação da legislação municipal. Isso nos revela que existe uma lacuna entre poder legislativo e esporte o que dificulta a interlocução entre governo e sociedade.

Por isso, fica claro que as mesmas deverão ser revistas e atualizadas levando em conta as verdadeiras necessidades, interesses e peculiaridades de cada município de forma a oportunizar a democratização do esporte com um direito. Salientamos que os ordenamentos legais são um dos fatores determinantes, não o único, para a democratização do esporte. Defendemos as políticas públicas de Estado e não as de 
governo que impulsionem a materialização destas políticas, as quais de forma regulamentadas oportunizarão políticas de acesso, incentivos, regulação e fomento.

Portanto a discussão do tema é extremamente relevante e necessária para que possamos levar o esporte junto as gestões municipais e buscar garanti-lo como direito social através de ordenamentos legais que propiciem de fato a democratização da prática esportiva em qualquer de suas dimensões com políticas públicas efetivas.

Diante disso, levando em conta o que contemplam as Leis Orgânicas estudadas, não é possível afirmar a existência de políticas públicas de esporte que são amparadas por determinação constitucional. Desse modo, se evidencia baixa capacidade de argumentação em defesa do esporte como política pública o que contribuem para que a política de esporte permaneça de forma secundária, sem prioridade como outras políticas sociais. Podemos ainda inferir que isso se deve a vários fatores, entre eles o próprio desinteresse, comodismo permeados por desconhecimento e incompetência dos envolvidos, nesse caso os agentes políticos que muitas vezes acabam por priorizar o interesse e a vaidade de pequenos grupos ou entidades, ora representados por seus legisladores.

Outrossim, considerando a limitação desse estudo, que foi exploratório, recomendamos que estudos futuros sejam realizados de forma que contemplem não só a análise da Lei Orgânica mas que sejam acrescidos em conjunto com os programas e ações realizados pelos municípios e pela própria associação, ora denominada UMMES para o desenvolvimento do esporte na região.

\section{REFERÊNCIAS}

ALMEIDA, B.C.; PAULA, S.L. Aplicação do modelo multidimensional-reflexivo para análise de uma entidade pública municipal: Autarquia de Esporte e Lazer do Recife (PE). Revista Gestão \& Políticas Públicas, v. 2, v. 1, p. 16-39, 2012. 
AMARAL, C. M. S. Gestor de instalações esportivas do município de São Paulo: perfil, formação e desempenho da função. 2014. 139 f. Dissertação de Mestrado Escola de Educação Física e Esporte da Universidade de São Paulo. São Paulo, 2014.

ANDRADE, C.A. et al. Análise documental das políticas públicas de incentivo às práticas físico-esportivas para pessoas com deficiência no Brasil: perspectivas para as paralimpíadas no Rio-2016. Revista Gestão \& Políticas Públicas, v. 4, n.1, p. 106-127, 2014.

ARAÚJO, S. M.; DOMINICI, K. R. L.; CARDOSO, G. M. Os Ordenamentos Legais do município de São Luís - MA: o esporte e o lazer em foco. CONGRESSO BRASILEIRO DE CÊNCIAS DO ESPORTE, 14. CONGRESSO INTERNACIONAL DE CIENCIAS DO ESPORTE, 3. Anais... Salvador, 2008.

ARAÚJO, S. M.; MAGALHÃES, Y. C. S. Políticas públicas de esporte e lazer em São Luís - MA: a gestão, participação popular e o controle social em discussão. In: ARAÚJO, S. M.; VIANA, R. N. A. Esporte e Lazer na Cidade de São Luís do Maranhão: elementos para construção de uma política pública. São Luís: EDUFMA, 2008.

AZEVEDO, P. H.; BARROS, J. F. O Nível de Participação do Estado na Gestão do Esporte Brasileiro como Fator de Inclusão Social de Pessoas Portadoras de Deficiência. Revista Brasileira de Ciência e Movimento, v. 12, n. 1, p. 77-84, 2004.

BARDIN, L. Análise de conteúdo. 5. ed. Lisboa: Edições 70, 2009.

BARROZO, A.F. et al Acessibilidade ao esporte, cultura e lazer as pessoas com deficiência. Universidade Presbiteriana Mackenzie CCBS - Programa de PósGraduação em Distúrbios do Desenvolvimento. Cadernos de Pós-Graduação em Distúrbios do Desenvolvimento, São Paulo, v.12, n.2, p. 16-28, 2012.

BASTOS, F.C. Gestão democrática e política municipal de esporte: o caso de Santana de Parnaíba. 2008. 169 f. Tese de Doutorado em Educação. Faculdade de Educação da Universidade de São Paulo, 2008.

Apontamentos sobre a participação da sociedade no desenvolvimento de políticas públicas de esporte no Brasil. Revista Intercontinental de Gestão Desportiva, v. 1, n. 1, p. 44-59, jan/jun 2011.

BIONDO, F. E. et al. Apontamentos sobre o poder público municipal: a Lei Orgânica do município e o regimento interno da câmara municipal. Disponível em: http:// www.colab.interlegis.leg.br .

BÖHME, M.T.S; BASTOS, F.C. Relatório de pesquisa em estados e capitais brasileiros. SIMPÓSIO INTERNACIONAL SOBRE POLÍTICAS PÚBLICAS PARA O ESPORTE DE ALTO RENDIMENTO, 2. Escola de Educação Física e Esporte, USP. Anais...São Paulo, 2016. 
BRAMANTE, A. C. Políticas de Lazer. In: GOMES, C. L. (Org.). Dicionário crítico do lazer. Belo Horizonte: Autêntica, p. 185-196, 2004.

BRASIL, Constituição (1988). Constituição da República Federativa do Brasil. Brasília, DF: Senado, 1988.

. Política Nacional do Esporte. Resolução $n^{\circ}$ 05/ Conselho Nacional do Esporte. 14 de junho de 2005.

BRASIL. Ministério da Saúde: Secretaria de Atenção à Saúde. Política Nacional de Saúde da Pessoa Portadora de Deficiência. Brasília: SAS, 2009a.

CARTA INTERNACIONAL DA EDUCAÇÃO FÍSICA E ESPORTE DA UNESCO de 1978.

CASTELLANI FILHO, L. A educação física no sistema educacional brasileiro: percurso, paradoxos e perspectivas. 1999. 185 f. Tese de Doutorado. Campinas: Faculdade de Educação Física, Unicamp. 1999.

CERVO, L. C.; BERVIAN, P. A. Metodologia científica. 5. ed. São Paulo: Pearson Prentice Hall, 2002.

CHEMIN, B. F. Políticas públicas de lazer: o papel dos Municípios na sua implementação. Curitiba: Juruá, 2007.

CONSTANTINO, J.M. Esporte, política e autarquia. Lisboa: Livros Horizonte, 1999.

CUNHA, L.M. Os espaços do desporto: uma gestão para o desenvolvimento humano. Coimbra: Almedina, 2007.

DACOSTA, L. P. (Org.). Atlas do Esporte no Brasil. Shape, 2005.

DA MATA, A.A.R. Políticas públicas de esporte e lazer na cidade de João Pessoa /Paraíba: uma análise do ordenamento legal. 2011. 209 f. Dissertação de Mestrado em Educação. Centro de Educação da Universidade Federal da Paraíba (PPGE/CE/UFPB), 2011 .

DAVIES, N. Educação nas leis orgânicas dos municípios fluminenses: pouca originalidade e muita cópia. Cadernos de Pesquisa, v.40, n.141, p.857-880, set./dez. 2010

ELIAS, F.C.O. et al. Esporte e Lazer no município de Raposa-MA: um direito a conquistar. CONGRESSO BRASILEIRO DE CIÊNCIAS DO ESPORTE, 15. CONGRESSO INTERNACIONAL DE CIÊNCIAS DO ESPORTE, 2. Anais... Salvador, 2007.

ESPÍRITO SANTO. Assembleia Legislativa. Programa Estadual de Fomento e Incentivo ao Esporte e Lazer e o Fundo de Incentivo ao Esporte e Lazer do Estado do Espírito Santo (Pró-esporte). Disponível em: http://www.al.es.gov.br/portal/ 
FEIX, E. O Esporte e o Lazer da Cidade e as fases da Vida. In: FERREIRA, M.P.A., MARCELINO, N.C. (Org.). Brincar, jogar, Viver: Programa Esporte Lazer da Cidade. Brasília: [s.ed.], 2007, v.1, p. 25-40.

GALINDO, A. G.; MORAES, R. S. Análise dos resultados obtidos no $1^{\circ}$ ciclo de conferências do esporte no estado do Amapá: subsídios iniciais visando a elaboração de políticas públicas para o esporte e o lazer. Revista Cinergis, Santa Cruz do Sul, v.5, n.2, p. 9-28, jul/dez. 2004.

GALINDO, A. G.; MORAES, R. S. Principais eixos temáticos de interesse social na discussão sobre políticas públicas para o esporte e lazer no estado do Amapá. In: REUNIÃO ANUAL DA SOCIEDADE BRASILEIRA PARA O PROGRESSO DA CIÊNCIA. 57, 2005, Fortaleza. Anais... Fortaleza: Sociedade Brasileira para o Progresso da Ciência-SBPC/Universidade Estadual do Ceará-UECE, 2005.

IBGE: Perfil dos Municípios Brasileiros - esporte 2003, 2006. Disponível em: http://www.ibge.gov.br/

Perfil dos Municípios Brasileiros - esporte 2009, 2010 b. Disponível em: http://www.ibge.gov.br/

Perfil dos Municípios Brasileiros: gestão pública 2009. Coordenação de população e Indicadores Sociais. Rio de Janeiro: IBGE, 2010.

IPEA. Atlas de Desenvolvimento Humano 2013 - Rio Branco. Consultado em 18 de Março de 2014, disponível em https://atlasbrasil.org.br/2013/pt/perfil_print/riobranco_ac

LIMA, P. C.; MOREIRA, F. S.; DIAS, D. C.; BAHIA, M.C.; ALMEIDA, A. C. P. C.; FONSECA, Z. V. D. Diagnóstico do Acesso ao Esporte e Lazer da População do Estado do Pará por meio das Políticas Públicas. In: SOARES, A.; LIBERATO, A.; LIMA, P. C.; SILVA, A. C.; CARSOSO, J. (Org.). Diagnóstico do Esporte e Lazer na Região Norte Brasileira - o existente e o necessário. Manaus: Edua, 2011.

LINHALES, M. A. Jogos da política, jogos do esporte: subsídios à reflexão sobre políticas públicas para o setor esportivo. In: MARCELLINO, Nelson Carvalho (Org.) Lazer e esporte: políticas públicas. Campinas: autores Associados, 2001.

LINHALES, M. e PEREIRA FILHO, J. R. Intervenção, conhecimento e mudança: a Educação Física, o Esporte e o Lazer nas políticas públicas. In: Educação Física \& Ciências do Esporte: intervenção e conhecimento. Florianópolis: CBCE, 1999.

MANHÃES, E. D. Política de Esportes no Brasil. Rio de Janeiro: Paz e Terra, 2002.

MAZZEI, L.C.; BASTOS, F.C.; FERREIRA, R.L.; BÖHME, M.T.S. Centros de treinamento esportivo par o esporte de alto rendimento no Brasil: um estudo preliminar. Revista Mineira de Educação Física, v. 1 (Esp.), n. 1, p. 1575-1584, 2012.

MELO, V. A. Lazer e minorias sociais. São Paulo: Ibrasa, 2003. 
MENEZES, V. G., OLIVEIRA, A. M., \& SOUZA, E. F. Gestão Desportiva e Política Pública na Região Metropolitana do Recife. Revista Brasileira de Educação Física e Esporte, v. 6, p. 219-230, 2012.

MEZZADRI, F. M. et al. Políticas públicas para o esporte e lazer nas cidades do Estado do Paraná. In MEZZADRI, F. M.; CAVICHIOLLI, F. R.; SOUZA, D. L. (Org.). Esporte e Lazer: subsídios para o desenvolvimento e a gestão de políticas públicas. Jundiaí: Fontoura, 2006. p. 43- 60.

MEZZADRI; CAVICHIOLLI; SOUZA, D. L. (Org.). Esporte e Lazer: subsídios para o desenvolvimento e a gestão de políticas públicas. Jundiaí: Fontoura, 2006.

MEZZADRI, F. M.; STAREPRAVO, F.; BASSO, D.; GUIMARÃES, L., \& REIS, R. Políticas públicas para o esporte e lazer nas cidades do estado do Paraná (pp. 43-60). In: MEZZADRI, F.M., CAVICHIOLLI, F.R., SOUZA, D.L. (Org.). Esporte e Lazer: subsídios para o desenvolvimento e a gestão de políticas públicas. Jundiaí: Fontoura, 2006.

MEZZADRI, F. M. Políticas Públicas para o Esporte e lazer: teorias e conceitos. In: MOTTA, Alexandre \& TERRA, Rodrigo. (Org.). Esporte, Lazer e políticas públicas na região dos Lagos. Rio de Janeiro: Ventura, p. 89-102, 2011.

MIGUEL, R.G.; STAREPRAVO, F.A. Análise das políticas públicas de esporte e lazer de Guarapuava-PR. ENCONTRO DA ALESDE (ASSOCIACIÓN LATINOAMERICANA DE ESTUDIOS SOCIOCULTURALES DEL DEPORTE. "Esporte na América Latina: atualidade e perspectivas", 1. Anais...UFPR. Curitiba, Paraná, Brasil. 2008.

MOREIRA, S. V. Análise documental como método e como técnica. In: DUARTE, J.; BARROS, A. (Org.). Métodos e técnicas de pesquisa em comunicação. São Paulo: Atlas, 2005. p. 269-279.

OLIVEIRA, Hosana Larissa Guimarães. Políticas públicas e ordenamento legal no âmbito do lazer e esporte na região nordeste e metropolitana da Bahia. In: SEMINÁRIO DE EDUCAÇÃO FÍSICA, 2008, Alagoinhas. Educação e corporalidade: conhecimento em rede. Anais... Alagoinhas: DEDC/UNEB, 2008. p. 76-79.

PEDROSO, C.A.M.Q.; MENEZES, V.G.; SARMENTO, J.P.; LEONILDO, L.F.S.; SANTOS, T.O.; COELHO, T.A.S. Gestão de equipamentos esportivos municipais: estudo de caso na cidade do Recife-PE. Revista Mineira de Educação Física, edição especial, n. 1, p. 1618-1630, 2012.

PERES, F.F. \& MELO, V.A. Espaço, lazer e política: desigualdades na distribuição de equipamentos culturais na cidade do Rio de Janeiro. Revista Digital efedeportes.com, 10(93), 2006. Disponível em: http://www.efdeportes.com/efd93/rio.htm

RICHARDSON, R.J. et al. Pesquisa social: métodos e técnicas. 3. ed. São Paulo: Atlas, 1999. 
ROCHA et al. Ordenamento legal e políticas públicas de esporte e lazer: o abismo entre gestão citadina e participação popular. In: CONGRESSO BRASILEIRO DE CIÊNCIAS DO ESPORTE, 15.; CONGRESSO INTERNACIONAL DE CIÊNCIAS DO ESPORTE, 2., 2007, Recife. Anais... Recife: CBCE, 2007.

SANTOS, E.S. Ambiente institucional e difusão do programa Segundo Tempo: uma análise da difusão regional de 2005 a 2009. Pensar a Prática, Goiânia, v. 16, n. 1, p. 1319, jan/mar. 2013.

SANTOS, A.B.; SILVA, T. D. \& OLIVEIRA, F. A. As políticas públicas de esporte do município de Jaguaquara/Bahia frente as prerrogativas da política nacional de esportes. Revista Intercontinental de Gestão Desportiva, Rio de Janeiro, v. 5, n. 1, p. 79-88, junho/2015.

SÃO PAUlO. Constituição. Constituição do Estado de São Paulo, Diário Oficial do Estado de São Paulo, São Paulo, 1989.

SÃO PAUlO. Ministério Público do Estado de São Paulo. Núcleo de Políticas Públicas - NPP, 2014. Disponível em: <https://www.mpesp.mp.br $>$.

SÃo PAULO. Governo do Estado de São Paulo. Secretaria de Planejamento e Gestão, 2015. Disponível em: < http://www.planejamento.sp.gov.br $>$.

SÃO PAULO. Secretaria de Estado de Esporte, Lazer e Juventude do Estado de São Paulo (SELJ), 2015b. Disponível em: http://www.selj.sp.gov.br.

SARMENTO, J. P. Qualidade na Gestão de Instalações Desportiva. Seminário de Gestão de Desporto. Universidade da Madeira, 2005. Consult. 25 de Fevereiro de 2014, disponível em https://pt.scribd.com/doc/31031114/Planeamento-e-Gestao-deInstalacoes-Desportivas-Dr-Jose-Pedro-Sarmento

SARMENTO, J. P. Quadros da cidadania Desportiva em Portugal. In J. O.Bento e J. M. Constantino (Eds.). Desporto e Municípios: Politicas, práticas e programas (p. 347368). Lisboa: Visão e Contextos, 2009.

SEADE. Fundação SEADE. Estado de São Paulo e suas Regionalizações, 2015.

SEBRAE. Perfil Econômico Regional - Regiões Selecionadas do Estado de São Paulo. São Paulo: SEBRAE, 2013.

SILVA, D. S.; SANTOS, M. I.; ÁVILA, M. A. Intersetorialidade nas políticas públicas de esporte e lazer no município de ilhéus-BA. Revista Conexões, v.11, n.3, p. 13-35, 2013.

SILVA, B.S.E. Perfil dos gestores esportivos do eixo clubísticos filiados ao sindiclube. Trabalho de Conclusão de Curso. Universidade Anhembi-Morumbi, 2012.

SOUSA, E. S., NORONHA, V., RIBEIRO, C., TEIXEIRA, D., FERNANDES, D. e VENÂNCIO, M. A. Sistema de monitoramento \& avaliação dos programas Esporte 
e Lazer da Cidade e Segundo Tempo do Ministério do Esporte. Belo Horizonte: O Lutador, 2010.

SOUZA, R. P. Caracterização e análise da gestão das instalações desportivas públicas não escolares do município de Rio Branco, Acre - Brasil. 2014. $165 \mathrm{f}$. Dissertação de Mestrado em Gestão Desportiva. Faculdade de Desporto da Universidade do Porto, 2014.

STAREPRAVO, F.A. Políticas públicas para o esporte e lazer: conselhos municipais de esporte e lazer e outras formas de participação direta. In: XV CONGRESSO BRASILEIRO DE CIENCIAS DO ESPORTE, 15 e CONGRESSO INTERNACIONAL DE CIÊNCIAS DO ESPORTE, 2. Anais... Recife: CBCE, 2007. Disponível em https://www.cbce.org.br/cd/resumos/283.pdf

TATAGIBA, L. Os conselhos gestores e a democratização das políticas públicas no Brasil. In: DAGNINO, E. (Org.). Sociedade civil e espaços públicos no Brasil. Rio de Janeiro: Paz e Terra, 2002.

THOMAS, J.; NELSON, J.; \& SILVERMAN, S. J. Métodos de pesquisa em atividades físicas. Porto Alegre: Artmed, 2007.

UMMES. União dos Municípios da Média Sorocabana de São Paulo, 2013. Disponível em: https://www.ummes.com.br.

UNESCO - Organização das Nações Unidas para a Educação, a Ciência e a Cultura. (1978). Carta Internacional da Educação Física e Esporte. Disponível em http://www.efmuzambinho.org.br/manifesto/carta68.htm.

VERONEZ, L. F. C. Quando o Estado joga a favor do privado: as políticas de esporte após a Constituição de 1988. Campinas. 2005. 370 f. Tese de Doutorado. Faculdade de Educação Física da Universidade Estadual de Campinas, 2005.

Descentralização e participação em gestões municipais de esporte e lazer. In: GOMES, L.C.; ISAYAMA, H. F. (Org.). Lazer, recreação e educação física. Belo Horizonte: Autência, p. 217-241, 2003.

\section{Endereço dos Autores:}

Marco Aurélio Gonçalves Nóbrega dos Santos

Av. Conceição, 531 - Centro

Chavantes - SP - 18.970-000

Endereço Eletrônico: marcoaurelio67@hotmail.com

Elisabete dos Santos Freire

Rua Cuiabá, 990 - Apto. 23 - Mooca

São Paulo -SP - 03.183-001

Endereço Eletrônico: elisabetefreire@uol.com.br 
Flávia da Cunha Bastos

EEFEUSP- Departamento de Esporte

Av. Prof. Mello Moraes, 65

São Paulo - SP - 05.508-030

Endereço Eletrônico: flaviacb@usp.br 